Objects prompt authentic scientific activities among learners in a museum programme

Achiam, Marianne; Simony, Leonora; Lindow, Bent Erik Kramer

Published in:

International Journal of Science Education

DOI:

10.1080/09500693.2016.1178869

Publication date:

2016

Document version

Early version, also known as pre-print

Document license:

Unspecified

Citation for published version (APA):

Achiam, M., Simony, L., \& Lindow, B. E. K. (2016). Objects prompt authentic scientific activities among learners in a museum programme. International Journal of Science Education, 38(6), 1012-1035.

https://doi.org/10.1080/09500693.2016.1178869 


\title{
Objects prompt Authentic Scientific Activities among Learners in a Museum Programme
}

Marianne Achiam*, Department of Science Education, University of Copenhagen, Denmark

Leonora Simony, Department of Science Education, University of Copenhagen, Denmark

Bent Erik Kramer Lindow, The Natural History Museum of Denmark, University of Copenhagen, Denmark

*corresponding author, achiam@ind.ku.dk, Department of Science Education, Øster Voldgade 3, 1350 Copenhagen, Denmark

\begin{abstract}
Although the scientific disciplines conduct practical work in different ways, all consider practical work as the essential way of connecting objects and phenomena with ideas and the abstract. Accordingly, practical work is regarded as central to science education as well. We investigate a practical, object-based palaeontology programme at a natural history museum to identify how palaeontological objects prompt scientific activity among upper secondary school students. We first construct a theoretical framework based on an analysis of the programme's palaeontological content. From this, we build our reference model, which considers the specimens used in the programme, possible palaeontological interpretations of these specimens, and the conditions inherent in the programme. We use the reference model to analyse the activities of programme participants, and illustrate how these activities are palaeontologically authentic. Finally, we discuss our findings, examining the mechanism by which the specimens prompt scientific activities. We also discuss our discipline-based approach, and how it allows us to positively identify participants' activities as authentic. We conclude by discussing the implications of our findings.
\end{abstract}




\section{Introduction}

Practical work is a key aspect of the endeavour of science. Different scientific disciplines have different ways of conducting practical work, ranging from the controlled laboratory interventions typical of the experimental sciences to the descriptive specimen studies and fieldwork typical of the historical sciences (Cleland, 2011; Gray, 2014); however, common to these approaches is that they are ways of gaining knowledge about the world by connecting the domain of objects, materials, and phenomena with the domain of ideas and the abstract. For this reason, practical work is commonly regarded as being central not only to science but to science education as well (Abrahams \& Reiss, 2012). This relationship is reflected in the widespread use of practical work in school science (Abrahams \& Millar, 2008), but out-of-school science education providers such as museums may also have an important role to play. Indeed, museums have a privileged relationship with a number of scientific disciplines because the practices and discourses of those disciplines have historically been intertwined with the collections of objects and specimens housed in the museum (Arnold, 1996; Livingstone, 2003). In particular, much practical work in the historical sciences is dependent on the collections of museums (Conn, 2010). Thus, with respect to expertise as well as access to objects and specimens, museums are in an ideal position to offer practical, object-based education programmes to support and complement school science. In the present study, we investigate one such programme which engages upper secondary school students in science through hands-on interactions with palaeontological specimens. We seek to identify the specific role(s) played by the scientific objects in these interactions, and to characterise the ways in which they can prompt scientific activities among participants.

\section{Engaging in Science with Objects}

What does it mean to 'engage in science with objects', and how can such engagement be observed and assessed? First, as suggested in the preceding section, science is not just one thing. This means that when we seek to understand how objects prompt engagement in science, we cannot simply invoke the idea of a universal scientific method featuring domainfree skills as a way to observe and assess this engagement. Different disciplines conduct investigations in different ways (Ault \& Dodick, 2010; Crawford, 2014); indeed, science is the variety of methods and techniques that scientists actually use to explore diverse phenomena - science is what scientists do (Rudolph, 2007). To understand what kinds of scientific engagement objects can prompt and support, we can thus look to the scientific community for whom the objects in question are sites for interpretation and sources of information. Such communities have developed disciplinary toolkits 'with established modes of inquiry, evidentiary criteria, and accepted patterns of analysis to help in their object-related work' (Bain \& Ellenbogen, 2002, p. 153). By appreciating what is important in a scientific discipline's use of objects, we can derive criteria for what constitutes authentic scientific activities with those objects among science learners. 


\section{Theoretical Framework}

Science is what scientists do. Accordingly, the first step of our investigation entails an a priori analysis of the palaeontological objects in the education programme under study, using palaeontological primary literature as a reference, in order to establish what constitutes authentic palaeontological activities. In other words, to understand what constitutes scientific engagement with palaeontological objects, we take a point of departure in the way palaeontology professionals engage with palaeontological objects.

However, we cannot understand the activities of programme participants just in terms of scientists' practices because the frames of meaning that support and drive the work of scientists do not necessarily exist in educational contexts (Achiam, 2013; Bain \& Ellenbogen, 2002). Rather, we may understand the educational situation as the product of a process of didactic transposition (cf. Chevallard, 1991) in which the practices of scientists are appropriated from the domain of research and transformed and translocated into the domain of education - in this case, an education programme in a museum. In order to account for this transformation and translocation, we construct a reference model (cf. Barbé, Bosch, Espinoza, $\&$ Gascón, 2005) based on the authentic palaeontological activities identified in the a priori analysis, but tailored to the reality of the educational situation we wish to approach (Figure 1). The second step of the investigation is the construction of this reference model, which constitutes our methodological proposal for the analysis (cf. Chevallard \& Bosch, 2013). The final step of the investigation is the analysis of the activities of the participants in the programme, using the reference model as an analytical lens.

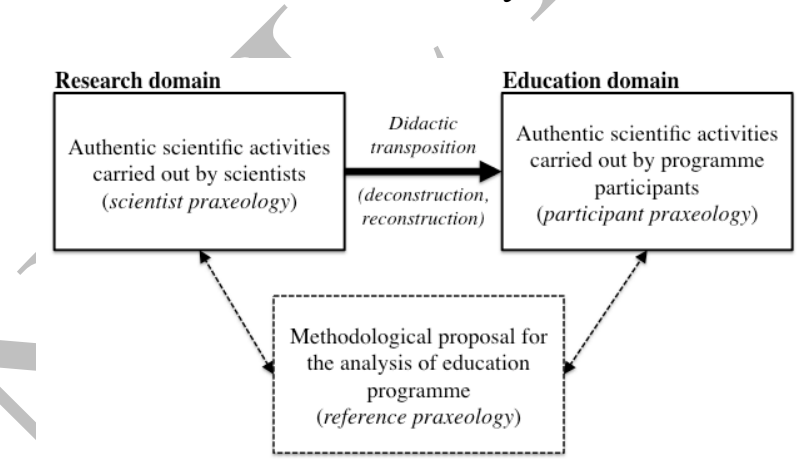

Figure 1. When educators design science education sequences, they carry out a process of didactic transposition. In this process, scientific practices from the research domain are deconstructed and reconstructed to adapt them to the education domain (solid arrow). To analyse the scientific activity of learners, it is necessary to construct a reference model that constitutes the methodological proposal for the analysis. This reference model must account for the original scientific activities of scientists as well as the particularities of the education situation in question (dashed arrows). 
Throughout this investigation, we use the theoretical notion of praxeology as a way to describe the authentic scientific practices of palaeontologists as well as those of the programme participants. Praxeology is a general model of human activity, which links the perceived characteristics of our environment to what we do and think. It consists of four elements: a task: any challenge or assignment we perceive in our surroundings; a technique: the way we accomplish that task; a technology: the discourse or rationale with which we explain our technique (literally the logos or discourse about the technique); and a theory: a more abstract set of concepts and arguments that justifies the technology (Chevallard, 2007). The task and technique elements may be collectively thought of as the 'know-how', while the technology and theory elements may collectively be thought of as the 'know-why'. For example, being able to recognise a quadratic equation and mobilise the correct formula to find its roots constitutes 'know-how', whereas understanding that the roots represent values of the independent variable $\mathrm{x}$ where the dependent variable $\mathrm{y}=0$, and that this corresponds to where the graph for $\mathrm{y}$ - a parabola - crosses the $\mathrm{x}$ axis, constitutes 'know-why'.

As hinted in this example, the notion of praxeology was originally developed in mathematics education research to describe student activities in classrooms. However, it has been used in a number of studies in science education research, both in school science (Kurnaz \& Sağlam Arslan, 2009; Madsen \& Winsløw, 2007; Tetchueng, Garlatti, \& Laube, 2008) and in out-of-school science (Mortensen, 2011; Achiam, 2013), to describe the activities of various actors including teachers, researchers, students, and museum visitors.

Finally, it is worth noting that although the term 'task' seems to imply a firmly controlled classroom setting with explicitly stated assignments for learners, the term simply denotes any kind of challenge or assignment we perceive in our environment. It may be helpful to think of a task in terms of affordance (Zhang \& Patel, 2006): The actions a given object or constellation of objects 'suggests' to a person or group of people because of the way they relate to it in a given situation (ef. Achiam, May, \& Marandino, 2014). The praxeology model can be thought of as a way to operationalise the connection between the characteristics of a given (educational) situation, and the things we do and think as a consequence of those characteristics.

Praxeology is a quite general way to describe human activity; it becomes a precise model only when applied to specific instances. Here, we describe the practices of palaeontologists working with specific objects and identified in the a priori analysis as scientist praxéologies. The subsequent tailoring of these praxeologies to address the educational situation in question we designate as reference praxeologies. Finally, we describe the observations, interpretations and reflections of the programme participants as observed in our data collection in terms of participant praxeologies (Figure 1). 


\title{
Method
}

\section{Object of Study}

The present study focuses on the palaeontology programme Evolution: From Dinosaur to Bird, a teaching sequence designed for upper secondary school students (16-18year-olds) visiting the Natural History Museum of Denmark ('the Museum'). The programme is a 90-minute interactive lesson that consists of 1) an introduction in the Museum's Feathers Gallery (approximately 15 minutes), 2) a classroom-based session with a brainstorm about feathers and their functions (approximately 20 minutes), 3) an exercise where participants compare a modern bird skeleton to a cast of a fossil Archaeopteryx (approximately 40 minutes), and finally 4) a rounding-off back in the exhibition (approximately 15 minutes). The lesson is described on the Museum's web site in the following way:

\begin{abstract}
How did birds evolve, and what did they evolve from? What information is available in a 145 million year old fossil? The evolution of birds is exemplary for our understanding of the concept of evolution. In this programme, the students examine and compare fossils of the dinosaur-bird Archaeopteryx with skeletons of modern birds. Observations of similarities and differences form the basis of a discussion of the evolutionary development from dinosaurs to birds. The programme begins and ends with a visit to the Museum's exhibitions (Natural History Múseum of Denmark, 2013, authors' translation).
\end{abstract}

Here, we investigate the 40-minute exercise where participants compare a modern bird skeleton to a fossil. We singled out this particular exercise for three main reasons: First, the objects used in the exercise are similar to those of scientists working on the same research question. Second, in the exercise, the educator provides the participants with the research question, and then withdraws to allow the participants to determine the method of investigation and interpretation. The exercise therefore allowed us to investigate how, specifically, the objects prompted investigation among the participants without the intervention of teachers and educators, and what trajectories of inquiry the participants chose to pursue. Third, based on the experience of the museum educator responsible for the programme (the third author), we judged the 40-minute exercise to be the part of the programme where participants were least likely to have prior knowledge or experience of the content. The exercise was thus the optimal component of the programme for investigating how objects prompt scientific activity. The preceding parts of the programme introduce participants to the idea that they will be working 'as scientists do' and establish the various functions of feathers in modern birds as a preface to discussing the possible functions of feathers in dinosaurs; these parts of the programme are substantially more educator-centred and less object-centred than the chosen exercise, and thus do not offer the same opportunities for us to observe how objects prompted activity.

In the exercise, the participants are given a skeleton of a common modern bird (e.g. Carrion Crow, Corvus corone; Herring Gull, Larus argentatus; or Common Buzzard, Buteo buteo) and a cast of a fossil Archaeopteryx lithographica (specifically a cast of the so-called 
Berlin specimen), and asked to find and list the differences they can observe between the modern bird and Archaeopteryx. After finding and listing the differences, the participants are asked to use these differences in a discussion of whether they think Archaeopteryx had been able to fly.

\section{A Priori Analysis of Programme Content}

The significance of Archaeopteryx is that it was the first fossil to be found that indicated the evolutionary origins of birds by having a 'reptilian' skeleton, but also unmistakably wearing feathers (Ostrom, 1975). Later, the fossil came to establish the now commonly accepted relationship between dinosaurs and birds, although the precise details of that relationship are still being debated (e.g. Lee \& Worthy, 2012). A number of recent finds from China of dinosaur fossils with feather imprints preserved now pre-date Archaeopteryx in geological time (e.g. Xu \& Zhang, 2005; Zhang et al., 2008; Hu et al., 2009). However, at the time of Archaeopteryx' discovery, feathers had hitherto been considered a key character of birds (Wellnhofer, 2004), and an adaptation for flight (Padian \& Chiappe, 1998). Accordingly, the discovery of the feathered Archaeopteryx raised the question of whether it had been capable of active, flapping flight. Accordingly, in our model of palaeontologists' practices, we consider the research question 'Was Archaeopteryx able to fly?' to be the point of departure of the scientist praxeologies. This question corresponds to the established mode of inquiry of comparative anatomy (von Bonin, 1946), in which the researcher compares shared anatomical features of extinct and extant organisms to postulate a common cause for them (Cleland, 2002). In the present case, we shall consider only comparisons made between the anatomy of Archaeopteryx and modern birds.

Table 1. Palaeontologists' comparisons of the features of a modern bird and a fossil Archaeopteryx and their interpretations with respect to Archaeopteryx' flight capability. These comparisons and interpretations are parsed into scientist praxeologies in the text (see e.g. Figure 2, which corresponds to row IX).

\begin{tabular}{|c|c|c|c|}
\hline & Modern bird & Archaeopteryx & Interpretation \\
\hline I & $\begin{array}{l}\text { Robust sternum and large } \\
\text { keel }\end{array}$ & Lack of sternum and keel & Contraindication (De Beer, 1954) \\
\hline II & Asymmetric feathers & Asymmetric feathers & Indication (Feduccia \& Tordoff, 1979) \\
\hline III & fused pygostyle & $\begin{array}{l}\text { Numerous tail vertebrae; long } \\
\text { tail }\end{array}$ & Contraindication (Gatesy \& Dial, 1996) \\
\hline IV & Large wing area & Large wing area & Indication (Yalden, 1971) \\
\hline $\mathrm{V}$ & No claws on front limbs & Claws on front limbs & Indication (Savile, 1957) \\
\hline VI & $\begin{array}{l}\text { Fan-like organisation of tail } \\
\text { feathers }\end{array}$ & $\begin{array}{l}\text { Frond-like organisation of } \\
\text { tail feathers }\end{array}$ & Indication (Wellnhofer, 2004) \\
\hline VII & Light, slender bones & Heavy, robust bones & Contraindication (Gatesy \& Dial, 1996) \\
\hline VIII & Light skull with beak & $\begin{array}{l}\text { Heavy skull with toothed } \\
\text { jaws }\end{array}$ & $\begin{array}{l}\text { Contraindication (Benson, Butler, } \\
\text { Carrano, \& O'Connor, 2012) }\end{array}$ \\
\hline IX & Fused clavicles (furcula) & Fused clavicles (furcula)* & Indication (Padian \& Chiappe, 1998) \\
\hline $\mathrm{X}$ & $\begin{array}{l}\text { Stiffened, shortened thoracic } \\
\text { vertebrae }\end{array}$ & Flexible thoracic vertebrae & Contraindication (Ostrom, 1979) \\
\hline
\end{tabular}

Pre-print version of Achiam, M., Simony, L., \& Lindow, B. E. K. (2016). Objects prompt authentic scientific activities among learners in a museum programme, published in International Journal of Science Education. Available at http://www.tandfonline.com/doi/abs/10.1080/09500693.2016.1178869 


\begin{tabular}{llll}
\hline XI & $\begin{array}{l}\text { Strongly reduced number of } \\
\text { bones in forelimbs }\end{array}$ & $\begin{array}{l}\text { Slightly reduced number of } \\
\text { bones in forelimbs }\end{array}$ & Indication (Kershaw, 1988) \\
\hline
\end{tabular}

*This is true of three Archaeopteryx specimens: the London, Thermopolis and Maxberg specimens.

To gain insight into what kinds of comparisons palaeontologists carry out, we first listed the features of modern birds that constitute their adaptations to flying (Kershaw, 1988) and that are visible to the naked eye on a modern bird skeleton. With this list as a point of departure, we compared a modern bird skeleton to an Archaeopteryx fossil, and identified eleven macroscopic similarities and differences between the two that were, likewise, visible to the naked eye. We then surveyed the palaeontological primary literature to find evidence of how palaeontologists have interpreted these similarities and differences, resulting in a list of eleven trajectories of inquiry related to comparative anatomy (Table 1). Finally, we parsed each of these trajectories into a scientist praxeology (an example is given in the following). The scientific validity of the scientist praxeologies was verified by the third author, who holds a doctorate in palaeontology, specifically bird evolution.

\section{Construction of the Reference Praxeologies}

The science knowledge and practices that are generated in research contexts represent the answers to the particular needs of those contexts and are formulated accordingly (Bosch \& Gascón, 2006). In educational contexts, the particular needs oflearners are quite different from those of scientists, and consequently, the reconstruction of science by learners is a response to another set of equally specific conditions. Therefore, if we were to use the activities of palaeontologists as a direct gauge of the activities of programme participants, we would undoubtedly find the latter to be a strongly reduced version of the former. The reference model is a way to avoid this reductionist approach; consider the following example, in which we illustrate the elaboration of one reference praxeology.

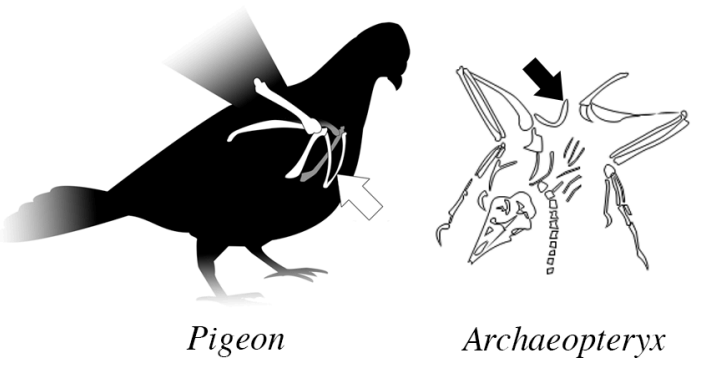

A

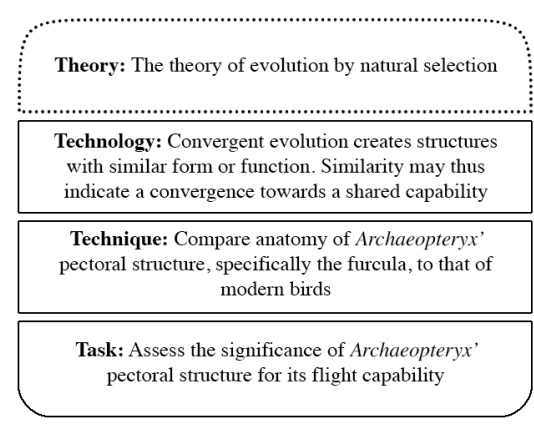

B

Figure 2. Scientist praxeology. The scientific observation of the furcula on a modern bird and its comparison to that of Archaeopteryx (here, the Thermopolis specimen) (A) can be described in a scientist praxeology (B). The scientist praxeology corresponds to Table 1, row IX. It describes the scientific task, the technique, the technology justifying the claim that Archaeopteryx could have been a flier, and the overarching theory that (implicitly) justifies the technology. Pigeon redrawn from Kershaw (1988).

Example: The furcula. The avian furcula, or wishbone (Figure 2A), is believed by scientists to 
be formed from a fusion of the clavicles. It is generally interpreted as an adaptation of the bird flight apparatus (Ostrom, 1979), where its role may vary from that of a strut or a brace to stabilise the pectoral girdle to that of a spring to enhance wing movement (Bock, 2013). Of the twelve existing Archaeopteryx specimens, only the London, Thermopolis and Maxberg specimens feature a robust, boomerang-shaped structure believed to be a strut-like furcula. However, the presence of the furcula in these three specimens has been interpreted to mean that Archaeopteryx was a flier (Ostrom, 1979; Padian \& Chiappe, 1998), while its absence in the other known specimens can be explained by incomplete fossilisation. This observation and interpretation can be summed up in the scientist praxeology shown in Figure 2B (corresponding to Table 1, row IX).

Palaeontologists are aware that fossils differ from each other due to their unique histories and that this affects what can be reliably predicted from them (Ault \& Dodick, 2010). For this reason, the observation and interpretation of the furcula in Archaeopteryx by palaeontologists is based on a careful extrapolation of observations of all twelve existing specimens. However, in the educational context of the school programme under investigation here, a decision was made to include Archaeopteryx solely in the form of casts of the Berlin specimen, which does not feature a visible furcula. The educator responsible for the programme, the third author, explained that although 'there is a clearly visible and wellpreserved furcula on the London specimen, [...] it looks like a roadkill and is difficult for the students to interpret' and he thus decided to use the tidier Berlin specimen (B. E. K. Lindow, personal communication, 29/08/13).

This decision is part of the process of deconstruction and reconstruction of science that goes on in the design of any education sequence; however, it is important to realise that didactic transposition does not (necessarily) produce a degraded version of the original scientific practice or knowledge. Rather, it should be thought of as a process that often improves the reorganisation of the practice or knowledge with the goal of making it more teachable and understandable (Chevallard \& Bosch, 2013). It is precisely the role of the reference model to account for such changes. In the present case, then, a more appropriate reference for the students activities would be the reference praxeology shown in Figure 3, which accounts for the fact that the programme features only the Berlin Archaeopteryx specimen, and that it cannot be observed, in this context, that Archaeopteryx may have had a furcula.

Finally, although in our readings of the scientific literature we did not find the invoked theory to be explicitly mentioned by the authors, we have included theory as an explicit part of the reference praxeology. This is because the Natural History Museum describes the programme Evolution: From Dinosaur to Bird as a means to contribute to participants' understanding of evolution; we thus wished to be sensitive to any occurrences of evolution theory (as well as other theoretical components) in our analysis of participants' activities and reflections.

In this way, we constructed eleven reference praxeologies; these reference praxeologies are based on the eleven scientist praxeologies identified in the a priori analysis and subsequently elaborated and modified to account for the specific conditions that characterised the school programme. In the following, we use these reference praxeologies as

Pre-print version of Achiam, M., Simony, L., \& Lindow, B. E. K. (2016). Objects prompt authentic scientific activities among learners in a museum programme, published in International Journal of Science Education. Available at http://www.tandfonline.com/doi/abs/10.1080/09500693.2016.1178869 
a lens to understand how objects prompt authentic scientific activities among the participants in the programme.

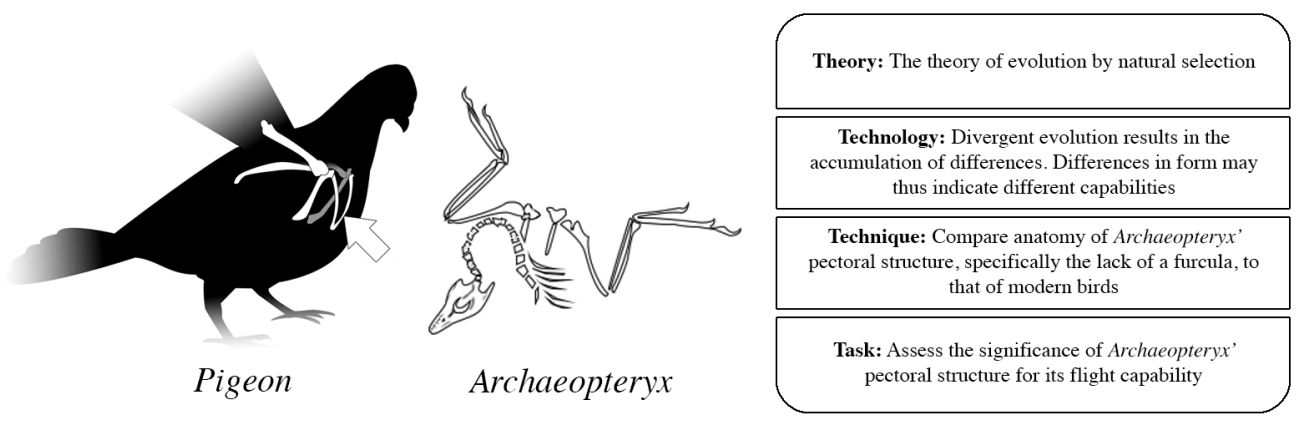

A

B

Figure 3. Reference praxeology. The observation of the furcula on a modern bird and its apparent lack on Archaeopteryx (here, the Berlin specimen) (A) can be summed up in the reference praxeology shown in (B). Here, the inference that Archaeopteryx was not a flier is justified by the technology of divergent evolution. Pigeon redrawn from Kershaw (1988).

\section{Data Collection}

In November and December of 2012, we observed, audio recorded and video recorded seven upper secondary school classes who had registered for the programme. Permission to record and observe had been obtained prior to the classes' arrival to the Museum; we reconfirmed this permission on their arrival. We followed the class and audio-recorded the introduction to the programme held in the Museum's Feathers Gallery. We then accompanied the class to the classroom, where the participants were divided into groups of three to five. Each group chose a table, and were supplied with a set of materials. We video-recorded one such group in each of the seven participating classes. We had set up the video camera (at a different table for each visit) prior to the entry of the participants to the classroom, and the group that sat at 'our' table was thus the group that we observed and filmed. In the following, these groups are designated as Group 1 through 7. Finally, we followed the class back into the Feathers Gallery for the final part of the programme, which we audio-recorded.

The educational significance of the programme Evolution: From Dinosaur to Bird for upper secondary school students is related to the programme's evolution biology content. Even though the Danish upper secondary school curriculum does not specifically mention palaeontology, it describes evolution biology as one of the core subjects that students must engage with practically, through the investigative and analytical methods proper to that subject (Danish Ministry of Education, 2014). Because there is a strong intersection between the methods of evolution biology and those of palaeontology, the programme Evolution: From Dinosaur to Bird offers teachers an opportunity to fulfil an important component of their curricular obligations. Indeed, informal interviews carried out with teachers who had brought their students to the Museum indicated that they attended the programme because they found it difficult to implement a practical exercise on evolution biology at school. 


\section{Analysis Procedure}

We used the six steps of theoretical thematic analysis to find themes in participants' discussions, using the eleven reference praxeologies (developed in the following sections) as our 'top down' or deductive framework (Braun \& Clarke, 2006). In the first step, we familiarised ourselves with the data by viewing the video footage and transcribing it verbatim. Second, we coded the data, using the eleven reference praxeologies as our focus. Third, we allocated the codes to themes, and in step four, we reviewed these themes, ensuring internal homogeneity and external heterogeneity. This confirmed the existence of nine themes corresponding to nine of the eleven reference praxeologies.

In step five, we refined the nine themes by organising them into participant praxeologies. It was necessary to make special note of instances of dialectical reasoning, in which arguments and activities were executed in several turns, interspersed between other events (cf. Nielsen, 2013). In other words, constructing the participant praxeologies sometimes entailed piecing together activities, gestures and verbal exchanges that were temporally detached from one another, yet in essence contiguous.

In this process, we identified three types of participant praxeologies: 1) warranted praxeologies, which closely resemble the corresponding reference praxeologies and are thus supported by the available data; 2) unwarranted praxeologies, which are based on techniques similar to those described in the reference praxeologies, but with technologies (and theories) that are not supported by the available data; and finally, 3) incomplete praxeologies, in which techniques similar to those described in the reference praxeologies are carried out, but are not explicitly justified in a technology by the participants. The presentation of the results, which constitutes the sixth and final step of the analysis, is structured around these three types of participant praxeologies.

\section{Results}

The seven groups of participants each carried out between five and nine praxeologies, resulting in a total of 50 'lived' praxeologies (Figure 4). Of these, 27 (or 54\%) were warranted, i.e. they consisted of a discernable technique, had an explicit technology that was supported by the data (and were thus aligned with the corresponding reference praxeology), and were used in the generation of a hypothesis of whether Archaeopteryx had been able to fly. A further 9 (or 18\%) participant praxeologies were unwarranted, i.e. they consisted of a discernable technique, had an explicit technology that was not supported by the available data (thus differing from the corresponding reference praxeology), and were used in the generation of a hypothesis of whether Archaeopteryx was able to fly. Finally, we observed 14 (or 28\%) incomplete participant praxeologies, i.e. instances where participants engaged in a technique based on the objects, but where they did not explicitly state their technology. In no case did we observe participants make explicit invocations of theory, neither the theory of evolution by natural selection nor other biological theories. We do not include as participant praxeologies those activities that were off-task, i.e. that were not related to the objects or the question of Archaeopteryx' flight capability. In the following sections, we provide examples of the three 
different categories of participant praxeologies, along the way comparing them to and contrasting them with the corresponding reference praxeologies.

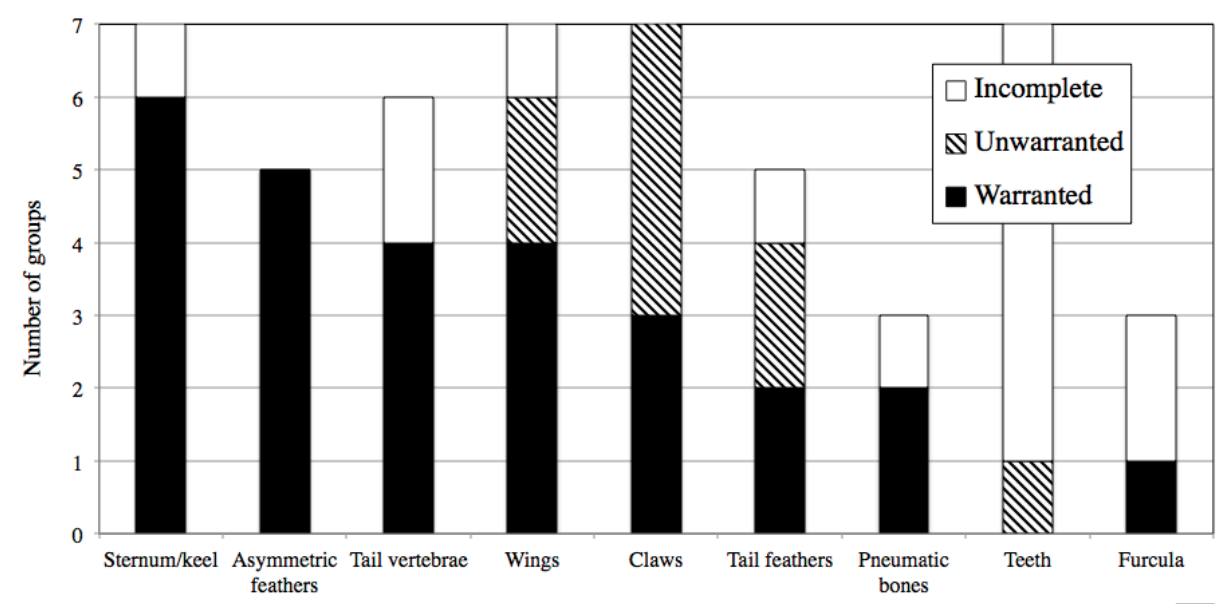

Figure 4. The frequency of the three different types of participant praxeologies across the seven groups of participants.

\section{Warranted Praxeologies}

An example of a warranted praxeology is given by the assessment of Archaeopteryx wing area with regards to its flight capability by Group 3. Recall that we designate as 'warranted' those participant praxeologies that are aligned with the reference praxeologies, and used in the generation of the participants' hypothesis. We first outline the scientist and reference praxeologies, and then follow with the example of a participant praxeology.

Scientist praxeology. Many of the existing Archaeopteryx specimens feature well-preserved feathered wings (Wellnhofer, 2004) that are elliptical in shape and rather similar to the wings of modern birds in appearance (Savile, 1957). The span and surface area of Archaeopteryx' wings relative to its body size are similar to those of modern woodland birds, e.g. pheasants or pigeons. Flight power vs. wing span calculations show that this wing configuration makes woodland birds efficient flyers at low to moderate speeds in dense vegetation, and accordingly, Archaeopteryx ' wing design is interpreted as an indication of its flight capability (Yalden, 1971) (Table 1, row IV).

Reference praxeology. In the context of the school programme, the modern bird is represented by a skeleton, and its wing span cannot be directly observed. Furthermore, aerodynamic principles are not commonly taught in upper secondary school (Pietsch, Bohland, \& Schmale, 2014), so a reference praxeology that assumes that participants are able to make aerodynamic calculations in the manner of researchers will almost certainly fail to capture the ways in which they engage in the task. A more appropriate reference for the participants' activities would be the praxeology shown in Figure 5, which entails estimating the area of the wings of the modern bird using the skeleton as a scaffold, and comparing this to the area of 
Archaeopteryx' wings. Accordingly, we can describe the reference praxeology regarding Archaeopteryx' wings as shown in Figure 5.

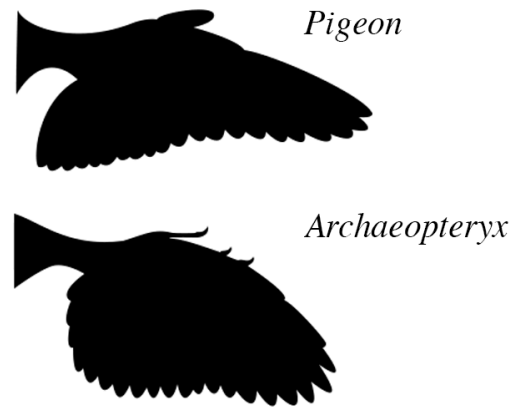

A

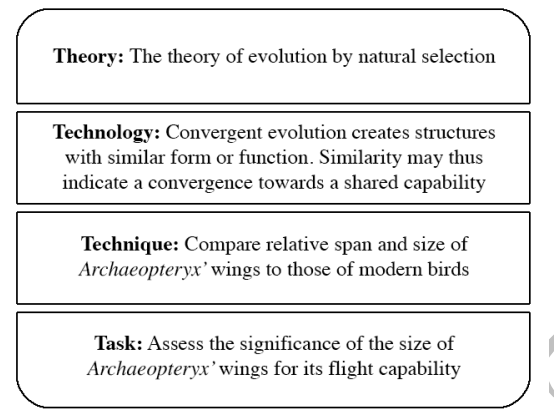

$\mathbf{B}$

Figure 5. Reference praxeology. The comparison of the relative size and span of Archaeopteryx' wings to those of modern birds (A) expressed as a reference praxeology (B). In this case, the inference that Archaeopteryx was a flier is justified by the technology of convergent evolution. Wings redrawn from Wellnhofer (2004).

Participant praxeology. In the following exchange, Group 3 provides an example of a comparison of the wing size of Archaeopteryx and a modern bird (pseudonyms are used):

Betsy: Aren't the wings approximately the same length? (Indicates forelimb bones of modern bird skeleton and Archaeopteryx.)

Bob: $\quad$ Yes.

(Some minutes go by, as the group discusses other features of the specimens.)

Betsy: It's a little annoying that we don't know what kind of feathers this one had (indicates modern bird skeleton), because this one (indicates Archaeopteryx) has very long feathers.

Adam: No, it doesn't. It has pretty small feathers, this one (indicates Archaeopteryx). That one (indicates modern bird skeleton) was probably a gull, so it probably had feathers of this size (indicates with hands how long he estimates gull feathers to be).

Betsy: $\quad$ [Archaeopteryx] has long feathers, it's clearly visible. This is a feather (points to imprint of feather on Archaeopteryx' wing. Takes parrot feather and superimposes it on Archaeopteryx' wing; see Figure 6A, left). Well?

Adam: That belongs to a parrot.

Betsy: I know.

Adam: $\quad$ A parrot is bigger than that (indicates Archaeopteryx).

Bob: $\quad$ I would agree that [Archaeopteryx] has long feathers.

(Some minutes go by, as the group discusses other features of the specimens.)

Adam: $\quad$ [Archaeopteryx] was mainly a runner. It has feathers for gliding and for jumping.

Bob: I don't think that's true, when it has feathers that long. [...] I mean, developing a big feathered tail and the long feathers that you see here (indicates length of Archaeopteryx' wing; see Figure 6A, right). It looks 
like... it looks like flight feathers. [...] Why would it have flight feathers if it couldn't fly?

The observations and interpretation of Group 3 are summed up in the participants' praxeology shown in Figure 6. The participants in this group use features of two modern birds, namely the length of a gull's forelimb and the length of a parrot's feather, to establish that Archaeopteryx' wing dimensions are consistent with flight capability. They are thus formulating a technology based on the comparison of wing areas and body sizes. The theory that explains this technology remains tacit. However, it is interesting to note the similarity of the argument made by Bob: 'It looks like flight feathers. [...] Why would it have flight feathers if it couldn't fly?' to the one made by palaeontologists Feduccia and Tordoff, who state that 'any argument that Archaeopteryx was flightless must explain selection for asymmetry in the wing feathers in some context other than flight' $(1979$, p. 1022). This argument is part of a technology that interprets the presence of Archaeopteryx asymmetric wing feathers as an indication of its flight capability, drawing on the principles of adaptiveness and vestigiality (Table 1 , row II).
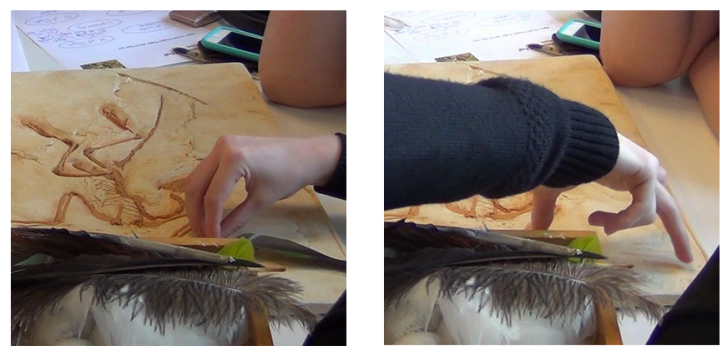

A

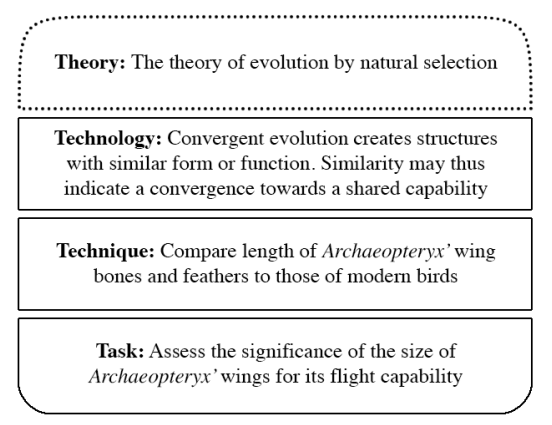

B

Figure 6. Participant praxeology. The participants compare the feather impressions on the Archaeopteryx fossil with a parrot feather (A, left) and gauge the length of Archaeopteryx' wing (A, right). Their technique and technology are summed up in a participant praxeology (B). Their inference that Archaeopteryx could have been a flier is justified by the technology of convergent evolution. The theory is not mentioned (dashed line).

\section{Unwarranted Praxeologies}

An unwarranted praxeology is exemplified by Group 2's interpretation of Archaeopteryx' claws on its front limbs as a contraindication of its flight capabilities. 'Unwarranted' praxeologies are those where the techniques lead to technologies that are not supported by the available data (and thus not aligned with the reference praxeology), but are still used in the generation of the participants' hypothesis. As in the preceding, we first outline the scientist and reference praxeologies, and then follow with the example of a participant praxeology.

Scientist praxeology. Because claws are an important indicator of avian habits, Archaeopteryx' claws have been studied by a number of researchers. The morphology of the claws on Archaeopteryx' front limbs are distinct from those of predators and perching birds, 
but resemble those of tree-climbing or trunk-clinging modern birds such as woodpeckers (Chatterjee \& Templin, 2003; Feduccia, 1993). Archaeopteryx' manual claws are accordingly interpreted as an indirect indication of its flight capabilities, because they may have allowed the animal to climb trees to reach a suitable height from which to launch itself into flight (Feduccia, 1993) (Table 1, row V).

Reference praxeology. In the context of the programme, the available bird skeletons do not include tree-climbing or trunk-clinging species. For this reason a more suitable reference for participants' trajectories of inquiry may be the comparison of the presence of claws on Archaeopteryx' wings with the presence of claws on the wings of other known flyers, e.g. bats (Figure 7A) or flying squirrels. This comparison could lead to the inference that Archaeopteryx, like modern bats, is capable of climbing and clinging to rough surfaces using the claws on its front limbs (Burnham, Feduccia, Martin, \& Falk, 2010); in other words, a case of convergent evolution (Figure 7B).

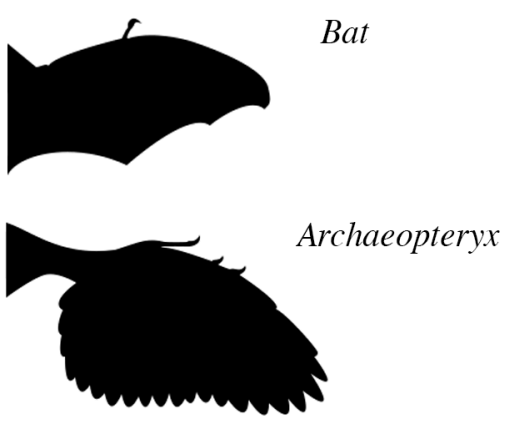

A

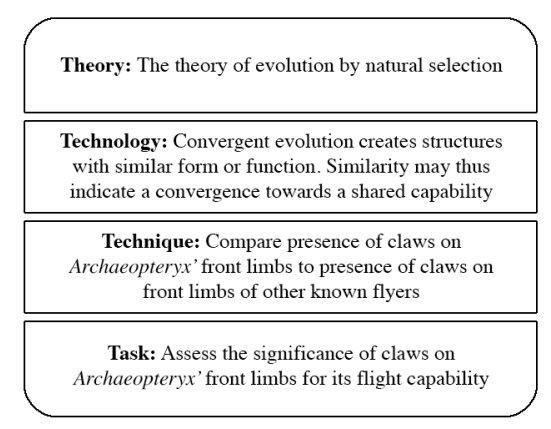

B

Figure 7. Reference praxeology. The comparison of the claws on Archaeopteryx' wings to those on the wings of modern bats (A) expressed as a reference praxeology (B). The presence of manual claws on both of these animals generates a technology based on convergent evolution towards the shared capability of clinging to rough surfaces before take-off or upon landing; in other words, an indirect indication of Archaeopteryx' flight capability. Archaeopteryx wing redrawn from Wellnhofer (2004); bat wing redrawn from Padian (1985).

Participant praxeology. An unwarranted praxeology is exemplified by Group 2 in their discussion of Archaeopteryx' manual claws:
Alan:
It's strange. This one doesn't have claws (indicates modern bird forelimb).
Those [bones] are completely covered (envelops forelimb of modern bird with hand; see Figure 8A, left), but there are claws there (points to Archaeopteryx) and only two [forearm bones]. There are three [forearm bones] there (points to modern bird).
Dyana: I don't think those could have been wings (about Archaeopteryx' forelimbs).
Camilla: Me neither. I'm not sure they were wings.
(Some minutes go by, and the museum educator asks the participants to formulate a hypothesis of whether or not Archaeopteryx had been able to fly on the basis of their findings.)
Alan: Was it able to fly? 
Alice: $\quad$ I don't know.

Camilla: $\quad$ It reminds me of those... The Land Before Time... those big birds that have claws underneath their feathers.

Alan: It just doesn't look like something that could fly with those [wings]. Maybe it could jump up and fly down?

Alice: It looks too clumsy.

Dyana: I think it's too short here (points to Archaeopteryx' wing).

Beatrice: $\quad$ Maybe it has...

Dyana: $\quad$ This one has feathers all the way to out here (indicates entire modern bird forelimb) and this one doesn't, because here, it has claws (indicates the area on Archaeopteryx' wing where claws emerge; see Figure 8A, right).

(Some minutes go by, as the group discusses other matters)

Alan: Who votes in favour of, and who votes against its ability to fly?

Dyana: $\quad$ I don't think it can fly.

Alice: $\quad$ It can't fly.

Camilla: $\quad$ I don't think so either.

Alan: What a bummer (group laughs).

Beatrice: But listen, its wings are too small! Its feathers only go to here [indicates the area on Archaeopteryx' wing where claws emerge], so it doesn't have anything to flap.

In this example, the members of Group 2 seem unable to reconcile the existence of claws on Archaeopteryx' front limbs with other potential functions of those limbs. This is surprising in view of their discussion of the pterosaurs of the Hollywood film The Land Before Time which indeed have claws on their front limbs as well as flight capability. The group members repeatedly state that the place where Archaeopteryx' claws emerge marks the limit of its feathers, although an inspection of the fossil shows that this is not the case. The observations and interpretations of Group 2 are summed up in the participant praxeology shown in Figure 8B.

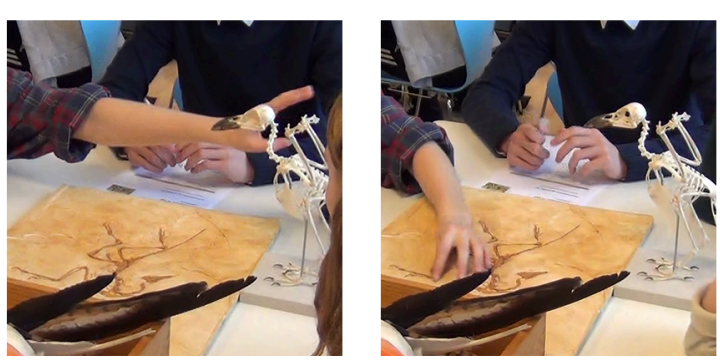

A

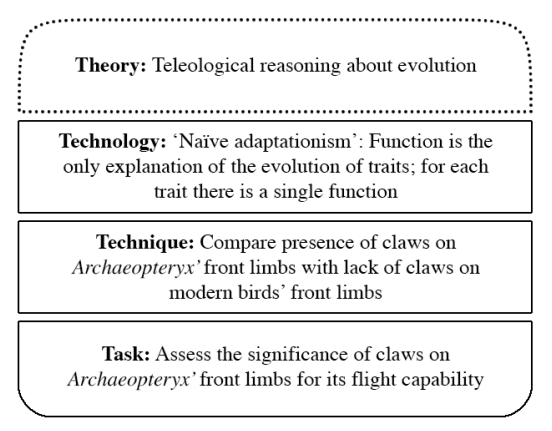

B

Figure 8. Participant praxeology. A participant from Group 2 outlines how tissue and feathers would envelop the forelimb bones on a living modern bird (A, left) and contrast this to the point on the front limb of Archaeopteryx where the claws emerge (A, right). Their technique and technology are summed up in a participant praxeology element (B). The participants make a nä̈ve adaptationist inference that Archaeopteryx could not have been a flier because its forelimbs also bear claws. The theory is not mentioned; however, naïve adaptationism is associated with teleological ways of reasoning about evolution (dashed line).

Pre-print version of Achiam, M., Simony, L., \& Lindow, B. E. K. (2016). Objects prompt authentic scientific activities among learners in a museum programme, published in International Journal of Science Education. Available at http://www.tandfonline.com/doi/abs/10.1080/09500693.2016.1178869 
A final example, this time of an incomplete praxeology, is the assessment by Group 5 of the bone structure of Archaeopteryx' tail with regards to its flight capability. Recall that we designate as 'incomplete' those participant praxeologies in which participants engage with the objects at the level of technique, but construct neither technology nor theory. As in the preceding, we first outline the scientist and reference praxeologies, and then follow with the example of a participant praxeology.

Scientist praxeology. A striking feature of Archaeopteryx is its long, flexible tail, which consists of a large number of vertebrae. This long tail would have handicapped it somewhat during flight by increasing drag (Norberg, 1995), but also because the mechanical linkages between the individual vertebrae probably hampered coordinated turning (Gatesy \& Dial, 1996). In comparison, a modern bird has a quite short, stiff tail with a reduced number of fused caudal vertebrae (pygostyle). This is advantageous in flight because it reduces drag and energy expenditure, but also because it reduces the part of modern bird's body weight that is far from its centre of gravity (cf. Zhou \& Li, 2010). Accordingly, Archaeopteryx' long tail is interpreted as a contraindication of flight capability (Table 1, row III).

Reference praxeology. In the programme, the participants do not have access to observing the mechanisms of muscular control of the tail vertebrae of birds and Archaeopteryx, as these mechanisms are not discernable from visual inspections of the specimens. A more appropriate reference for the participant praxeology could be the technique of comparing Archaeopteryx with a range of other known fliers (Figure 9A) to support a technology that the lack of long bony tails in these fliers is an indirect contraindication of Archaeopteryx' flight capability (Figure 9B).

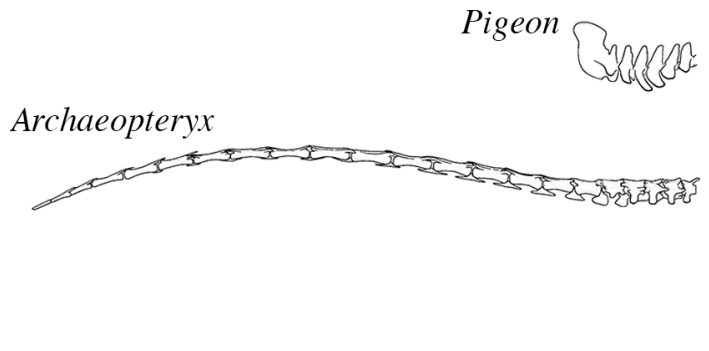

A

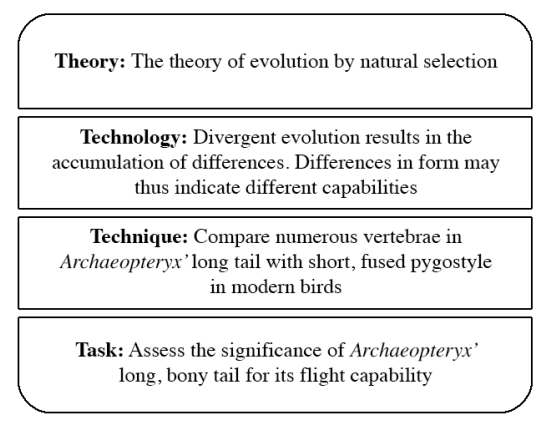

B

Figure 9. Reference praxeology. The comparison of Archaeopteryx' long bony tail to the pygostyle of a modern bird (A) and its interpretation, expressed as a reference praxeology (B). Archaeopteryx tail and bird pygostyle redrawn from Gatesy and Dial (1996).

Participant praxeology. An example of an observation of the difference between the structures of the tails of the two specimens is given by Group 5:

Benjamin: $\quad$ That one has a tail (points to Archaeopteryx' tail vertebrae; see Figure 10A, left.)

Anna: $\quad$ Yes. 
Benjamin: That one does not have a tail. That's not a tail, that thing! (points to pygostyle on modern bird skeleton).

Anna: $\quad$ There might have been feathers on it.

Benjamin: But feathers aren't a tail.

Anna: $\quad$ Yes they are.

Arthur: $\quad$ That one has a tail bone (indicates Archaeopteryx' tail vertebrae). A long tail bone.

Benjamin: $\quad$ Feathers aren't a tail; they're tail feathers. A dog has a tail, since it can control its tail (waves arm to simulate movement of dog tail; see Figure 10A, right). That one (points to Archaeopteryx) can also control its tail; that one (points to modern bird skeleton) cannot.

The observations of Group 5 are summed up in the participant praxeology shown in Figure 10. The members of the group carry out the technique of comparing the bone structures of the two specimens. Although they interpret Archaeopteryx' long bony tail as an appendage that could be controlled, and the tail feathers of a modern bird as something it cannot control, they do not use these observations to generate a technology with respect to Archaeopteryx' flight capability (although we could speculate that the group would have predicted that Archaeopteryx' tail could have functioned as a rudder in flight, had they considered it); the lack of a technology causes us to categorise this participant praxeology as incomplete.
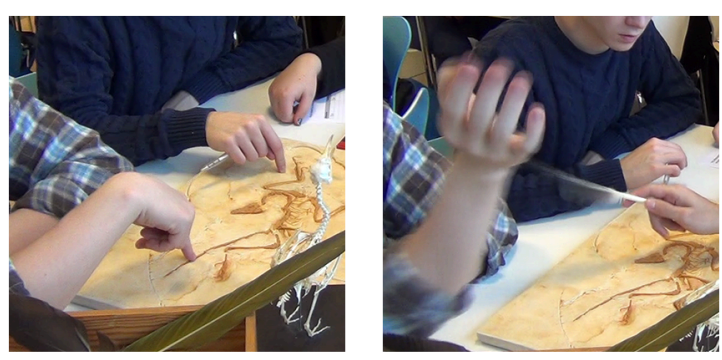

A

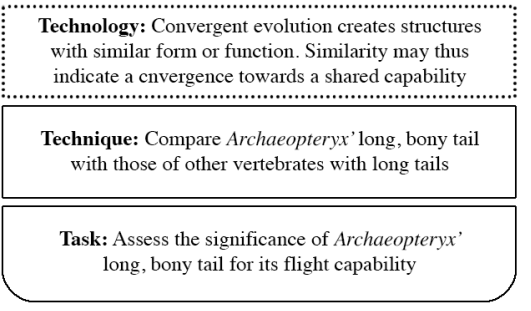

B

Figure 10. Participant praxeology. A participant from Group 5 points out the long, bony tail of Archaeopteryx (A, left) and compares it to the tail of a dog, waving his arm to show the controlled movement of a dog's tail (A, right). The participants' technique is summed up in a participant praxeology (B). They do not explicitly discuss the implications of using a dog's tail as a modern analogue of Archaeopteryx' tail, but their implied technology (dashed line) is that Archaeopteryx was able to fly based on its tail's similarity with those of modern vertebrates (convergent evolution).

\section{Summary}

The results of the study show that the two scientific specimens, the Archaeopteryx fossil and the bird skeleton, were able to prompt a number of different activities among participants in a palaeontology programme. Although the overarching activity of comparing the two specimens and using this comparison to discuss Archaeopteryx' flight capability was given by the museum educator, the participants themselves determined their exact trajectories of inquiry. We identified nine different trajectories of inquiry or participant praxeologies 
across the seven groups of participants. Although these participant praxeologies were not always warranted (i.e. supported by the data) nor complete (i.e. had an explicit technology), they were all prompted by the features of the specimens and the courses of action or techniques these features 'suggested' to the participants because of the way they related to them. Additionally, more than half (54\%) of the activities carried out by the participants led to the generation of technologies that were scientifically authentic (warranted) based on the criteria set out in the preceding sections. That is, in more than half the events observed in the present study, the specimens and the context of the research question 'Was Archaeopteryx able to fly?' prompted participants to carry out scientifically authentic activities and generate scientifically authentic explanations.

\section{Discussion}

We begin the discussion by revisiting our research focus (a characterisation of how palaeontological objects prompt scientific activities among learners) and discussing our findings. Based on this discussion, we present and discuss an argument for utilising an objectspecific, discipline-based approach to understanding object-based learning. In conclusion, we offer our perspectives on the implications of this observation.

\section{How do Palaeontological Objects Prompt Scientific Activity?}

In our study of the programme Evolution: From Dinosaur to Bird, we found that palaeontological specimens were capable of prompting scientifically authentic activities because of the way participants related to them in the context of the museum programme. The finding that scientific objects are capable of prompting activity is not new (e.g. Dierking \& Holland, 1996; Gurian, 1999; Triquet \& Laperrière, 1999); what is significant here is the finding that the objects prompted activities and reflections that were recognisable from the viewpoint of the scientific discipline, as well as the mechanism of that prompting.

At a very basic level, the mechanism by which the Archaeopteryx fossil and the bird skeleton invited comparison can be understood in terms of perceptual psychology: Things that are close together and things that look similar tend to be perceptually grouped together by humans (Ware, 2000). In other words, the most basic affordance of the juxtaposition of Archaeopteryx and the bird skeleton, namely that of comparing and contrasting, may be based on a fundamental human tendency. This observation seems disappointing: What is scientifically authentic about an activity based on a universal human ability? Our response is twofold. First, the method of comparative anatomy itself originated in a situation that is somewhat similar to the one in which the participants in Evolution: From Dinosaur to Bird found themselves: When dissecting a porpoise that had accidentally blundered up the river Thames, anatomist Edward Tyson noted the strong similarity between the porpoise and quadruped mammals (Gribbin, 2002). He wrote about the porpoise:

[...] when the skin and flesh was taken off, the fore-fins did very well represent an Arm, there being the Scapula, an os Humeri, the Ulna, and Radius, and bone of the Carpus, the Metacarp, and 5 digiti curiously jointed (Tyson, 1680, cited in Gribbin, 2002, p. 147). 
It could thus be argued that although comparison is the most basic activity objects suggest to humans, it is at the same time what provided the rudiments of the now-established scientific method of comparative anatomy. We thus argue that in Evolution: From Dinosaur to Bird, there is something scientifically authentic about the participants' activity of comparing the two specimens, even if the activity is a fundamental human one.

Second, we recall that affordances are constituted not just by objects, but equally by what the learner brings to the encounter. We therefore conjecture that the research question posed by the educator: 'Was Archaeopteryx able to fly?' was what turned the comparison into an authentic comparative anatomy activity by giving direction and purpose to the participants' trajectories of inquiry. In other words, it shaped the suggestive character of the specimens by changing the way the participants related to them, thereby constituting the comparative anatomy affordances of the situation. These affordances were manifested in the tasks perceived and carried out by the participants (e.g. the assessment of wing size or the presence of forelimb claws for flight capability) as well as in the technologies used by participants to rationalise their techniques; technologies that were in many cases based on notions of convergent and divergent evolution.

We thus argue that it is the specific nature of the specimens together with the research question that prompts specific palaeontological activities among participants. In other words, the objects, participants, and research question together formed the rich setting that gave rise to what Dierking (2002, p. 5) describes as the 'contextually driven effort to find meaning in the real world'. Dierking observes how such meaning making cannot easily be decontextualised from the direct experience with the objects; indeed, in the present case, we saw how the objects helped define the task, and provided the participants with knowledge and skills that would likely have been unavailable from their mental representations alone (cf. Zhang \& Patel, 2006). We thus concur with Dierking's (2002) suggestion that object-based learning should be understood as the processes by which learners interact with objects to create new understandings, rather than those understandings, seen in isolation.

This discussion in turn prompts us to consider to what extent our findings can be generalised. Can they be extended to other object-based education situations based on comparative anatomy, or perhaps even further, to situations that involve a broader range of palaeontological practices, or even as far as to situations generally based on the historical sciences? Given the fundamental nature of the comparative anatomy mechanism described in the preceding, it seems likely that any comparable set of palaeontological specimens, e.g. hominid skulls (Thomson \& Beall, 2008) or vertebrate forelimb bones (Nadelson et al., 2009), can prompt the activity of comparing and finding similarities and differences. However, as we can infer from the preceding discussion, the specific trajectories of inquiry (or praxeologies) undertaken in such activities would be specific to the particular objects, because the physicalgeometric structure of those objects would strongly co-determine the possible action sequences (Zhang \& Patel, 2006). This means that if we broaden our perspective further, to consider other kinds of object-based palaeontological education situations, we are at the same time including a more diverse range of objects as well as the variety of actions suggested by them. For example, the palaeontological study of trace fossils involves inferring the behaviour 
and ecology of organisms from their fossilised trackways by studying details such as stride length, depth profile, and degree of overlap (Falkingham, 2014). Based on the present study, we conjecture that providing science learners with a suitable research question along with trackway fossils with appropriate physical-geometric properties would similarly suggest action sequences (or praxeologies) that are recognisable from a palaeontological point of view, although they would of course be qualitatively different from the activities we observed here. This means that what is generalisable from the present study is perhaps not only how objects prompt activity, but also that they prompt activity in ways that are recogniseable from the perspective of the historical sciences, namely the activities of description, comparison, and interpretation. We hypothesise that the limits of this generalisability largely coincide with the limits of the historical sciences because, unlike the experimental sciences, the historical sciences employ description and interpretation as their crucial means of understanding objects as scientific evidence (cf. Gould, 1989).

\section{A Discipline-Based Focus}

We have taken a strongly discipline-specific perspective on what it means to do science. It is interesting to note that had we taken a more discipline-general point of view, using behaviours such as observation, inference, prediction, and classification as indicators (cf. Ault \& Dodick, 2010), we would have observed a higher occurrence of scientific activity. Arguably, there is a trade-off between the broad generaliseablity and the epistemological depth of criteria for scientific activity. Consider the following example, in which Allen (2002) analysed museum visitors' conversations in an exhibition about frogs. Allen used 16 discipline-general categories to classify visitors' learning-talk, e.g. 'feature = pointing out some concrete aspect or property of the exhibit' (p. 274) or 'prediction = stated expectation about what will happen' (p. 275). Using these categories, Allen found that visitors enagaged in learning activity at $83 \%$ of the exhibit elements at which they stopped. Although Allen's methods and results are not directly comparable to ours, the two studies do illustrate how criteria for learning activity that are ' $\mathrm{few}$ in number and highly generalizeable across exhibitions' (Allen, 2002, p. 261) result in high frequencies of observed learning activities, while criteria for activity that are discipline-specific and strongly context-bound result in relatively fewer instances of observed scientific activity. Conversely, we can also see how a discipline-specific approach may provide a more well-defined picture of the scientific knowledge or practice at stake. As discussed in the introduction, scientists engineer inquiry methods that fit particular contexts by using imagery, imagination, and relevant knowledge (Ault \& Dodick, 2010). Our discipline-specific lens allowed us to capture similar scientific behaviours among the programme participants in the present study, responding to recent calls from museum research to direct the attention of learners towards the practices that give object meaning in disciplinary communities (Schauble, 2002).

We have argued how the discipline-specific focus taken in this study had definite advantages in terms of focusing our attention on the salient aspects of participants' engagement in science with objects. However, our discipline-focus also raises the question of the utility of the reference model (Figure 1): If authentic science entails engaging learners in 
investigations that are similar to those carried out by scientists (Crawford, 2015), why can these learner investigations not just be understood in terms of scientists' practices? Why is it necessary to use the 'filter' of the reference model to evaluate learners' activities?

A general answer to this question is that the reference model is the tool that allows us, as educational researchers, to step outside the system under investigation (Bosch \& Gascón, 2006; Chevallard \& Bosch, 2013). The scientific knowledge and practices produced by scientists are formulated according to specific conditions and as answers to particular needs; when this knowledge and these practices undergo didactic transposition to become elements in educational situations they are subsequently (re)produced by science learners as answers to different, but equally particular needs. For this reason, the knowledge and practices of scientists cannot be used as a direct reference for the knowledge and practices of science learners; they may be the reference point of the institution behind the educational situation (i.e. the museum or school) but not of the researchers who consider the educational institution as an object of study (Bosch \& Gascón, 2006). The reference model is the epistemological standpoint explicitly taken by the researcher to clarify her or his analytical proposal.

In the particular case of Evolution: From Dinosaur to Bird, there was a strong resemblance between the participants' praxeologies and those carried out by scientists because the programme was purposefully designed by a palaeontologist to closely emulate scientific, specimen-based comparative anatomy. For us, the researchers, this meant that the scientist's praxeologies identified through the a priori analysis became strongly imprinted on the reference praxeologies we constructed; however, it remained necessary for us to consider the particular conditions and requirements manifest in the programme in our construction of the reference praxeologies. Conversely, one could also imagine educational situations in which the process of didactic transposition has altered the knowledge and practices in question to such a great extent that they are barely recognisable from the viewpoint of science research (see e.g. Mortensen, 2010); in such cases, the reference model becomes all-important in understanding the significance of the resulting activities of science learners.

In summary, we agree with Chevallard (1991) when he maintains that science education research should go beyond examining how the learner learns; research should consider the entire process by which knowledge and practices from the domain of science become knowledge and practices in the domain of education. Such investigations include explicit attention to the original object of scientific knowledge or practice as well as to the conditions that precipitated it (Achiam, 2013) to understand the re-organisation of the knowledge/practice that is carried out to improve it from a teaching/learning point of view.

\section{Final Remarks}

We have argued that it is the nature and juxtaposition of the palaeontological specimens and their framing by a palaeontological research question that prompts participants to think and behave as actual palaeontologists. This finding is important in the light of recent research that argues the advantages of engaging science learners in investigations that are similar to those carried out by scientists and that involve answering research questions under current scientific investigation by the research community (cf. Crawford, 2015). Recent 
policy documents from the EU (European Commission, 2007) and US (National Research Council, 2012) similarly recommend an authentic science approach to teaching science. We suggest that natural history museums potentially have much to contribute to the construction of authentic science learning experiences within the historical science disciplines because of their long-standing commitment to education, to collecting scientific objects and specimens, and to conducting research with these objects and specimens (cf. Conn, 2010; Livingstone, 2003).

\section{Acknowledgments}

We wish to acknowledge our constructive conversations with professors Carl Winsløw and Marianna Bosch in the early stages of this manuscript, the support of the ATD research community, and the kind participation of seven Danish secondary school groups. We wish to warmly thank two anonymous reviewers for their constructive suggestions.

\section{Cited Literature}

Abrahams, I., \& Millar, R. (2008). Does practical work really work? A study of the effectiveness of practical work as a teaching and learning method in school science. International Journal of Science Education, 30(14), 1945-1969. doi: 10.1080/09500690701749305

Abrahams, I., \& Reiss, M. J. (2012). Practical work: Its effectiveness in primary and secondary schools in England. Journal of Research in Science Teaching, 49(8), 10351055. doi: 10.1002/tea.21036

Achiam, M. (2013). A content-oriented model for science exhibit engineering. International Journal of Science Education, Part B, 3(3), 214-232. doi: $10.1080 / 21548455.2012 .698445$

Achiam, M., May, M., \& Marandino, M. (2014). Affordances and distributed cognition in museum exhibitions. Museum Management and Curatorship, 29(5), 461-481. doi: $10.1080 / 09647775.2014 .957479$

Allen, S. (2002). Looking for learning in visitor talk: A methodological exploration. In G. Leinhardt, K. Crowley \& K. Knutson (Eds.), Learning conversations in museums (pp. 259-303). Mahwah: Lawrence Erlbaum Associates.

Arnold, K. (1996), Presenting science as product or as process: Museums and the making of science. In S. Pearce (Ed.), Exploring Science in Museums (pp. 57-78). London: Athlone Press.

Ault, C. R., \& Dodick, J. (2010). Tracking the footprints puzzle: The problematic persistence of science-as-process in teaching the nature and culture of science. Science Education, 94(6), 1092-1122. doi: 10.1002/sce.20398

Bain, R., \& Ellenbogen, K. M. (2002). Placing objects within disciplinary perspectives: examples from history and science. In S. G. Paris (Ed.), Perspectives on objectcentered learning in museums (pp. 153-169). Mahwah: Lawrence Erlbaum Associates. 
Barbé, J., Bosch, M., Espinoza, L., \& Gascón, J. (2005). Didactic restrictions on the teacher's practice: The case of limits of functions in Spanish high schools. Educational Studies in Mathematics, 59, 235-268. doi: 10.1007/0-387-30451-7_9

Benson, R. B. J., Butler, R. J., Carrano, M. T., \& O'Connor, P. M. (2012). Air-filled postcranial bones in theropod dinosaurs: Physiological implicationa and the 'reptile'bird transition. Biological Reviews, 87, 168-193.

Bock, W. (2013). The furcula and the evolution of avian flight. Paleontological Journal, 47(11), 1236-1244. doi: 10.1134/S0031030113110038

Bosch, M., \& Gascón, J. (2006). Twenty-five years of the didactic transposition. ICMI Bulletin, 58, 51-65.

Braun, V., \& Clarke, V. (2006). Using thematic analysis in psychology. Qualitative Research in Psychology, 3(2), 77-101. doi: 10.1191/1478088706qp063oa

Burnham, D. A., Feduccia, A., Martin, L. D., \& Falk, A. R. (2010). Tree climbing - a fundamental avian adaptation. Journal of Systematic Palaeontology, 9(1), 103-107. doi: $10.1080 / 14772019.2010 .522201$

Chatterjee, S., \& Templin, R. J. (2003). The flight of Archaeopteryx. Naturwissenschaften, 90, 27-32.

Chevallard, Y. (1991). La transposition didactique: Du savoir savant au savoir enseigné. [Didactic transposition: From scholarly knowledge to taught knowledge]. Grenoble: La Pensée Sauvage, Editions.

Chevallard, Y. (2007). Readjusting didactics to a changing epistemology. European Educational Research Journal, 6(2), 131-134. doi: 10.2304/eerj.2007.6.2.131

Chevallard, Y., \& Bosch, M. (2013), Didactic transposition in mathematics education. In S. Lerman (Ed.), Encyclopedia of Mathematics Education. Berlin: Springer.

Cleland, C. E. (2002). Methodological and epistemic differences between historical science and experimental science. Philosophy of Science, 69(3), 447-451. doi: $10.1086 / 342455$

Cleland, C. E. (2011). Prediction and explanation in historical natural science. The British Journal for the Philosophy of Science, 62(3), 551-582. doi: 10.1093/bjps/axq024

Conn, S. (2010). Do museums still need objects? Philadelphia: University of Pennsylvania Press.

Crawford, B. A. (2014). From inquiry to scientific practices in the science classroom. In N. G. Lederman \& S. K. Abell (Eds.), Handbook of research on science education (Vol. 2, pp. 515-541). New York: Routledge.

Crawford, B. A. (2015). Authentic science. In R. Gunstone (Ed.), Encyclopedia of Science Education (pp. 113-115). Dordrecht, Heidelberg, New York, London: Springer.

Danish Ministry of Education. (2014). Biologi - stx. [National biology curriculum for upper secondary school]. Retrieved 20/11/13 from http://www.emu.dk/

De Beer, G. R. (1954). Archaeopteryx lithographica: A study based upon the British Museum specimen. London: British Museum (Natural History).

Dierking, L. D. (2002). The role of context in children's learning from objects and experiences. In S. G. Paris (Ed.), Perspectives on object-centered learning in museums (pp. 3-18). Mahwah: Lawrence Erlbaum Associates. 
Dierking, L. D., \& Holland, D. (1996). Getting inside visitors' heads: Utilizing interpretive carts as a mechanism for analyzing visitor conversations. Visitor Studies: Theory, Research, and Practice, 7(1), 19-25.

European Commission. (2007). Science education now: A renewed pedagogy for the future of Europe. Luxembourg: Office for Official Publications of the European Communities.

Falkingham, P. L. (2014). Interpreting ecology and behaviour from the vertebrate fossil track record. Journal of Zoology, 292(4), 222-228. doi: 10.1111/jzo.12110

Feduccia, A. (1993). Evidence from claw geometry indicating arboreal habits of Archaeopteryx. Science, 259(5096), 790-793. doi: 10.2307/2880833

Feduccia, A., \& Tordoff, H. B. (1979). Feathers of Archaeopteryx: Asymmetric vanes indicate aerodynamic function. Science, 203(4384), 1021-1022. doi: 10.2307/1747485

Gatesy, S. M., \& Dial, K. P. (1996). From frond to fan: Archaeopteryx and the evolution of short-tailed birds. Evolution, 50(5), 2037-2048. doi: 10.2307/2410761

Gould, S. J. (1989). Wonderful life. The Burgess Shale and the nature of history. New York: W. W. Norton \& Company.

Gray, R. (2014). The distinction between experimental and historical sciences as a framework for improving classroom inquiry. Science Education, 98(2), 327-341. doi: $10.1002 /$ sce. 21098

Gribbin, J. (2002). Science: A history 1543-2001. London: Penguin Books.

Gurian, E. H. (1999). What is the object of this exercise? A meandering exploration of the many meanings of objects in museums. Daedalus, 128(3), 163-183. doi: $10.2307 / 20027571$

Hu, D., Hou, L., Zhang, L. \& Xu, X. (2009). A pre-Archaeopteryx troodontid theropod from China with long feathers on the metatarsus. Nature, 461, 640-643. doi: $10.1038 /$ nature 08322

Kershaw, D. R. (1988). Animal Diversity. London: Chapman \& Hall.

Kurnaz, M. A., \& Sağlam Arslan, A. (2009). Using the Anthropological Theory of Didactics in physics: Characterization of the teaching conditions of energy concept and the personal relations of freshmen to this concept. Journal of Turkish Science Education, 6(1), 72-88.

Lee, M. S., \& Worthy, T. H. (2012). Likelihood reinstates Archaeopteryx as a primitive bird. Biology letters, 8(2), 299-303. doi: 10.1098/rsbl.2011.0884

Livingstone, D. N. (2003). Putting science in its place. Geographies of scientific knowledge. Chicago: The University of Chicago Press.

Madsen, L. M., \& Winsløw, C. (2007). Relations between university teaching and research in physical geography and mathematics. International Journal of Science and Mathematics Education, 7, 741-763.

Mortensen, M. F. (2010). Museographic transposition: The development of a museum exhibit on animal adaptations to darkness. Éducation \& Didactique, 4(1), 119-137.

Mortensen, M. F. (2011). Analysis of the educational potential of a science museum learning environment: visitors' experience with and understanding of an immersion exhibit. International Journal of Science Education, 33(4), 517-545. doi:

$10.1080 / 09500691003754589$

Pre-print version of Achiam, M., Simony, L., \& Lindow, B. E. K. (2016). Objects prompt authentic scientific activities among learners in a museum programme, published in International Journal of Science Education. Available at http://www.tandfonline.com/doi/abs/10.1080/09500693.2016.1178869 
Nadelson, L., Culp, R., Bunn, S., Burkhart, R., Shetlar, R., Nixon, K., \& Waldron, J. (2009). Teaching evolution concepts to early elementary school students. Evolution: Education and Outreach, 2(3), 458-473. doi: 10.1007/s12052-009-0148-X

National Research Council. (2012). A framework for K-12 science education: Practices, crosscutting concepts, and core ideas. Washington, DC: National Academies Press.

Natural History Museum of Denmark. (2013). Undervisningstilbud til gymnasier. [Education programmes for upper secondary school]. Retrieved 03/10/13 from http://snm.ku.dk/skole-oggymnasietjenesten/gymnasier/undervisning/book_et_undervisningsforloeb/

Nielsen, J. A. (2013). Dialectical features of students' argumentation: A critical review of argumentation studies in science education. Research in Science Education, 43(1), 371-393. doi: 10.1007/s11165-011-9266-x

Norberg, U. M. (1995). How a long tail and changes in mass and wing shape affect the cost for flight in animals. Functional Ecology, 9(1), 48-54. doi: 10.2307/2390089

Ostrom, J. H. (1975). The origin of birds. Annual Review of Earth and Planetary Sciences, 3, 55-77.

Ostrom, J. H. (1979). Bird flight: How did it begin? Did birds begin to fly "from the trees down" or "from the ground up"? Reexamination of Archaeopteryx adds plausibility to an "up from the ground" origin of avian flight. American Scientist, 67(1), 46-56.

Padian, K., \& Chiappe, L. M. (1998). The origin and early evolution of birds. Biological Reviews, 73(1), 1-42. doi: 10.1111/j.1469-185X.1997.tb00024.x

Pietsch, R. B., Bohland, C. L., \& Schmale, D. G. (2014). To fly or not to fly: Teaching advanced secondary school students about principles of flight in biological systems. Journal of Biological Education, 49(1), 53-63. doi: 10.1080/00219266.2014.882381

Rudolph, J. (2007). An inconvenient truth about science education. The Teachers College Record. Retrieved December 18, 2013, from http://www.tcrecord.org

Savile, D. B. O. (1957). Adaptive evolution in the avian wing. Evolution, 11(2), 212-224. doi: $10.2307 / 2406051$

Schauble, L. (2002). Cloaking objects in epistemological practices. In S. G. Paris (Ed.), Perspectives on object-centered learning in museums (pp. 235-241). Mahwah: Lawrence Erlbaum Associates.

Tetchueng, J. L., Garlatti, S., \& Laube, S. (2008). A context-aware learning system based on generic scenarios and the Theory in Didactic Anthropology of knowledge. International Journal of Computer Science \& Applications, 5(1), 71-87.

Thomson, N., \& Beall, S. C. (2008). An inquiry safari: What can we learn from skulls? Evolution: Education and Outreach, 1, 196-203. doi: 10.1007/s12052-007-0026-3

Triquet, E., \& Laperrière, M. (1999). Etudier les fossiles au musée. La spécificité des objets et du discours muséal comme point d'ancrage des apprentissages. [Studying fossils in the museum. The specificity of the objects and the museal discourse as an achor point for learning]. Aster, 29, 147-170.

von Bonin, G. (1946). Types and similitudes. An enquiry into the logic of comparative anatomy. Philosophy of Science, 13(3), 196-202. doi: 10.2307/184893 
Ware, C. (2000). Information visualization: Design for perception. San Diego: Academic Press.

Wellnhofer, P. (2004). The plumage of Archaeopteryx: feathers of a dinosaur. In P. J. Currie, E. B. Koppelhus, M. A. Shugar \& J. L. Wright (Eds.), Feathered dragons: Studies on the transition from dinosaurs to birds (pp. 282-300). Bloomington: Indiana University Press.

Xu, X. \& Zhang, F. (2005). A new maniraptoran dinosaur from China with long feathers on the metatarsus. Naturwissenschaften, 92, 173-177. doi: 10.1007/s00114-004-0604-y

Yalden, D. W. (1971). The flying ability of Archaeopteryx. Ibis, 113(3), 349-356.

Zhang, J., \& Patel, V. L. (2006). Distributed cognition, representation, and affordance. Pragmatics \& Cognition, 14(2), 333-341. doi: 10.1075/pc.14.2.12zha

Zhang, F., Zhou, Z., Xu, X., Wang, X. \& Sullivan, C. (2008). A bizarre Jurassic maniraptoran from China with elongate ribbon-like feathers. Nature, 455, 1105-1108. doi:10.1038/nature07447

Zhou, Z., \& Li, F. Z. Z. (2010). A new Lower Cretaceous bird from China and tooth reduction in early avian evolution. Proceedings of the Royal Society B: Biological Sciences, 277(1679), 219-227. doi: 10.1098/rspb.2009.0885 